\title{
Inadequate vitamin D status is associated with lower food plus supplemental intake of vitamin D in children of South Asian ethnicity living in the National Capital Region of Canada
}

\author{
Stephen P.J. Brooks, W.M. Nimal Ratnayake, Isabelle Rondeau, Eleonora Swist, Kurtis Sarafin, and Hope A. Weiler
}

\begin{abstract}
Vitamin D status, measured in a Vitamin D Standardization Program certified laboratory, was assessed among children of South Asian and European ethnicity living in the national capital region of Canada to explore factors that may account for inadequate status. Demographic information, dietary and supplemental vitamin D over $30 \mathrm{~d}$ prior to measurement of serum 25-hydroxyvitamin D (25OHD), and anthropometry were measured (age 6.0-18.9 y; $n$ = 58/group; FebruaryMarch 2015). No group related differences in age, height and body mass index (BMI) Z-scores or in food vitamin D intakes were observed. Standardized serum 25OHD was lower in South Asian children (mean \pm SD: $39.0 \pm 16.8$ nmol/L vs. European: $58.4 \pm 15.8 \mathrm{nmol} / \mathrm{L})$. A greater proportion of South Asian children had serum $25 \mathrm{OHD}<40 \mathrm{nmol} / \mathrm{L}(56.9 \mathrm{vs} .8 .6 \%, P<0.0001)$ and fewer took supplements ( $31 \mathrm{vs.} 50 \%, P=0.0389$ ). In a multi-factorial model $\left(r^{2}=0.54\right)$, lower vitamin $\mathrm{D}$ status was associated with overweight/obese BMI and older age (14-18 y); no interaction with ethnicity was observed. Lower vitamin D status was associated with lower total vitamin D intake only in South Asian children. This study reinforces the importance of public health actions towards meeting vitamin D intake recommendations among those of high-risk deficiency.
\end{abstract}

Novelty:

- A higher proportion of South Asian vs. European children had inadequate vitamin D status.

- Lower vitamin D status was associated with a BMI in the overweight/obese range.

- Lower vitamin D status was associated with lower total vitamin D intake in South Asian but not European children.

Key words: vitamin D, children, South Asian, winter, Canada, Vitamin D Standardization Program, VDSP.

Résumé : Le statut en vitamine $\mathrm{D}$, mesuré dans un laboratoire certifié du Programme de normalisation de la vitamine $\mathrm{D}$, est évalué chez des enfants d'origine sud-asiatique et européenne vivant dans la région de la capitale nationale du Canada; le but est d'explorer les facteurs pouvant expliquer un statut inadéquat. Dans un groupe ( $n=58,6,0-18,9$ ans), on évalue en février-mars 2015 les informations démographiques, les caractéristiques anthropométriques, la vitamine D alimentaire et supplémentaire pendant 30 jours avant la mesure de la 25-hydroxyvitamine D sérique (25OHD). On n'observe aucune différence liée à l'âge, à la taille et aux cotes Z de l'indice de masse corporelle (IMC) ou dans les apports alimentaires en vitamine D. La 25OHD sérique standardisée est plus faible chez les enfants sud-asiatiques (moyenne \pm ET : $39,0 \pm 16,8 \mathrm{nmol} / \mathrm{L}$ vs. les enfants européens : $58,4 \pm$ $15,8 \mathrm{nmol} / \mathrm{L}$ ). Une plus grande proportion d'enfants sud-asiatiques présentent un niveau sérique de $25 \mathrm{OHD}<40 \mathrm{nmol} / \mathrm{L}(56,9 \mathrm{vs}$. $8,6 \%, P<0,0001)$ et une plus faible proportion prennent des suppléments ( 31 vs. $50 \%, P=0,0389$ ). Dans un modèle multifactoriel $\left(r^{2}=0,54\right)$, un statut en vitamine D plus faible est associé à un IMC en surpoids/obésité et à un âge supérieur (14-18 ans); aucune interaction avec l'ethnicité n'est observée. Un statut en vitamine D plus faible est associé à un apport total plus faible en vitamine D chez les enfants sud-asiatiques. Cette étude renforce l'importance des actions de santé publique pour répondre aux recommandations d'apport en vitamine $\mathrm{D}$ chez les personnes à haut risque de carence. [Traduit par la Rédaction]

Les nouveautés :

- Une proportion plus élevée d'enfants sud-asiatiques que d'enfants européens présente un statut en vitamine D inadéquat.

- Un statut en vitamine D inférieur est associé à un IMC dans la plage de surpoids/obésité.

- Un statut plus faible en vitamine $\mathrm{D}$ est associé à un apport total plus faible en vitamine D chez les enfants sud-asiatiques mais pas chez les enfants européens.

Mots-clés : vitamine D, enfants, sud-asiatique, hiver, Canada, Programme de normalisation de la vitamine D, VDSP.

Received 9 March 2021. Accepted 16 August 2021.

S.P.J. Brooks, W.M.N. Ratnayake, ${ }^{*}$ E. Swist, K. Sarafin, and H.A. Weiler. Bureau of Nutritional Sciences, Food Directorate, Health Canada, Ottawa, ON K1A 0L2, Canada.

I. Rondeau. Bureau of Food Surveillance and Science Integration, Food Directorate, Health Canada, Ottawa, ON K1Y 0M1, Canada.

Corresponding author: Stephen P.J. Brooks (email: steve.brooks@hc-sc.gc.ca).

${ }^{*}$ Retired.

All Rights Reserved. "Inadequate vitamin D status is associated with lower food plus supplemental intake of vitamin D in children of South Asian ethnicity living in the National Capital Region of Canada." Health Canada. Adapted and reproduced with permission from the Minister of Health, 2021. This work is licensed under a Creative Commons Attribution 4.0 International License (CC BY 4.0), which permits unrestricted use, distribution, and reproduction in any medium, provided the original author(s) and source are credited. 


\section{Introduction}

The prevalence of inadequate vitamin $\mathrm{D}$ status in a population is assessed by the percentage of individuals with serum 25-hydroxyvitamin D (25OHD) falling below an accepted threshold. A threshold value of $40 \mathrm{nmol} / \mathrm{L}$, determined by the Institute of Medicine in the US, corresponds to the Estimated Average Requirement (EAR) of 400 IU of exogenous vitamin D daily for people in the general population over 1 year of age, and assumes minimal sun exposure (Ross et al. 2011). While national surveillance data has shown the majority of Canadians 6-79 years of age have 25OHD concentrations above $40 \mathrm{nmol} / \mathrm{L}$ (Brooks et al. 2017; Langlois et al. 2010), disparities exist in non-white Canadians with $42 \%$ of adults and 15.4 to $35.5 \%$ of children having 25OHD below $40 \mathrm{nmol} / \mathrm{L}$ (Brooks et al. 2017; Whiting et al. 2011). In that analysis, all Canadians of non-European descent were categorized as nonwhite but the sample size for each non-white group was too small to enable group-specific identification of modifiable factors related to vitamin D status. Specific sampling of groups potentially at risk of inadequate vitamin D status is, therefore, important.

In Canada, South Asian ethnicity represents the largest visible minority sector (6\% of the total population (Statistics Canada 2017)). Vitamin D status is of concern in this group since adults have mean $25 \mathrm{OHD}$ values approximately $40 \%$ lower than those of Europeans (Nagasaka et al. 2018; Sulistyoningrum et al. 2012). In addition, $27 \%-29 \%$ of females and $36 \%-44 \%$ of males have $250 \mathrm{HD}<40 \mathrm{nmol} / \mathrm{L}$ in the fall and spring, respectively - values that are much higher than those of European Canadians (5\%-10\% in the fall and spring, respectively; Nagasaka et al. 2018). South Asian ancestry is the strongest independent correlate of vitamin D status, while accounting for recent exposure to solar UV beta radiation, sex, melanin, dietary intakes, and age (Sham et al. 2015). These data suggest that lower vitamin D status is not necessarily seasonal in South Asian adults. Similar data are not available for children of South Asian ethnicity.

Adiposity is an important factor related to 25OHD levels (Greene-Finestone et al. 2017; Whiting et al. 2011) and may play a significant role in ethnic-related differences but the relationship is not simple. For example, Sulistyoningrum et al. (2012) found that visceral adiposity was a stronger determinant of the ethnicrelated divergence in vitamin $\mathrm{D}$ status among South Asian and European adults compared with other fat depots even through BMI did not differ from Europeans. Compared with Europeans, children of South Asian ethnicity have greater fat mass as early as 5-7 years of age (Shaw et al. 2007) and this difference increases with age independent of country of residence (Hudda et al. 2017; Lee et al. 2014; Rosenbaum et al. 2013; Shaw et al. 2007). In addition, South Asian children at a given BMI for age, have greater fat mass than do European children (Eyre et al. 2017; Nightingale et al. 2013; Rosenbaum et al. 2013). In Canadian children, vitamin D status declined with increasing BMI (Greene-Finestone et al. 2017) but the range differed with ethnicity. In non-whites, $42 \%$ of children in the obese range had $25 \mathrm{OHD}<40 \mathrm{nmol} / \mathrm{L}$ versus $25.8 \%$ for the nonobese. Comparable values for white children were 20.7 and $6.5 \%$, respectively. Whether South Asian children residing in Canada have increased rates of inadequate vitamin D status, even if BMI is within the healthy range, requires clarification. Therefore, the objective of this study was to assess vitamin D status among children of South Asian and European ethnicity in Canada, and to explore whether exogenous intakes and BMI are implicated as potential modifiable factors.

\section{Methods}

\section{Study design, recruitment and population}

This study was conducted in the National Capital Region of Canada (latitude $45.4^{\circ} \mathrm{N}$ ) between February 28 and March 15,
2015, thus minimizing recent sun exposure and location of residence as confounders of vitamin D status. Participants in this analysis were recruited through newspaper and local advertisements. Eligibility criteria were healthy children 6.0-18.9 years of age of South Asian (Bangladesh, India, Nepal, Pakistan or Sri Lanka), or European ethnicity residing in Ottawa, Ontario or Gatineau, Quebec. Children with known diabetes were excluded. Of the 201 children that completed a consent form, 55 did not participate further. Of those who attended one of the clinics, the following subjects were excluded from the final analysis: $n=2$ of mixed ethnicity; $n=10$ aged $>18.9 \mathrm{y} ; n=16$ who traveled to a warm sunny country within 2 months prior to the clinic visit; and $n=2$ with no recorded height and weight measurements (final $n=116$; Fig. 1). No statistical differences were observed between included and excluded subjects based on ethnicity, sex or age (Supplementary Table $S 1^{1}$ ). The study protocol was reviewed and approved by the Health Canada and Public Health Agency of Canada Research Ethics Board (REB 2013-019H). All procedures were conducted according to the guidelines laid down in the Declaration of Helsinki and the Tri-Council Policy Statement on Ethical conduct for Research Involving Humans (Canadian Institutes of Health Research Natural Sciences and Engineering Research Council of Canada and Social Sciences and Humanities Research Council 2018). Each participant or their parent gave written consent; minors also gave their assent prior to commencing the study measurements.

Research visits were conducted between 0730 and $1100 \mathrm{~h}$, participants were asked to arrive fasted for $10 \mathrm{~h}$. Blood $(5 \mathrm{~mL})$ was sampled and serum stored at $-80{ }^{\circ} \mathrm{C}$ until analysis of serum 25OHD. Weight and standing height were measured using standard procedures and used to calculate BMI. BMI was evaluated using Z-scores based on the World Health Organization (WHO) growth reference (WHO 2013) and categories (healthy, overweight, obese). Ethnicity, country of origin, and if applicable time residing in Canada were surveyed.

\section{Dietary and supplemental intake questionnaire}

Participants were e-mailed a food frequency questionnaire (FFQ) in either English or French and asked to complete it at home before the clinic visit; bilingual dietitians were present at the clinic to verify the FFQ as well as address missing data or unusual responses. The FFQ was previously used in a study of South Asian adults (Nagasaka et al. 2018) and adapted for appropriate serving sizes for children. If the FFQ was not completed prior to the visit, it was completed at the clinic visit. For all ages, the FFQ could be completed with parental assistance or filled out by the parent (72\% of the total FFQs involved the parent). The FFQ targeted a period $30 \mathrm{~d}$ prior to the visit and included foods known to contribute to vitamin D intakes (e.g., fatty fish, milk, fortified plant beverages, margarine, and eggs). Yogurt, yogurt beverage, cheese, kheer and paneer, mixed dishes, beef, chicken and pork were also included in the FFQ. Data were converted into the number of servings of each food category and vitamin D intakes expressed in IU per day using the 2010 Canadian Nutrition File (Government of Canada 2015). Portion sizes were based on previous analyses of the Canadian Community Health Survey Cycle 2.2 (Tugault-Lafleur and Black 2019). Supplement use was surveyed as yes/no and where applicable dose, frequency and Natural Health Product Number collected to verify dosage. Dietary and total vitamin $\mathrm{D}$ intakes were expressed as quartiles given that the data would not reflect true intakes.

\section{Skin pigmentation}

Skin colour was measured at the inner upper arm to reflect constitutive pigmentation using a portable Minolta Smart Probe 400 colorimeter (IMS Inc., Millford, CT). Three measurements were taken and the average expressed according to the International

\footnotetext{
${ }^{1}$ Supplementary data are available with the article at https://doi.org/10.1139/apnm-2021-0203.
} 
Fig. 1. Flow diagram of participant recruitment.

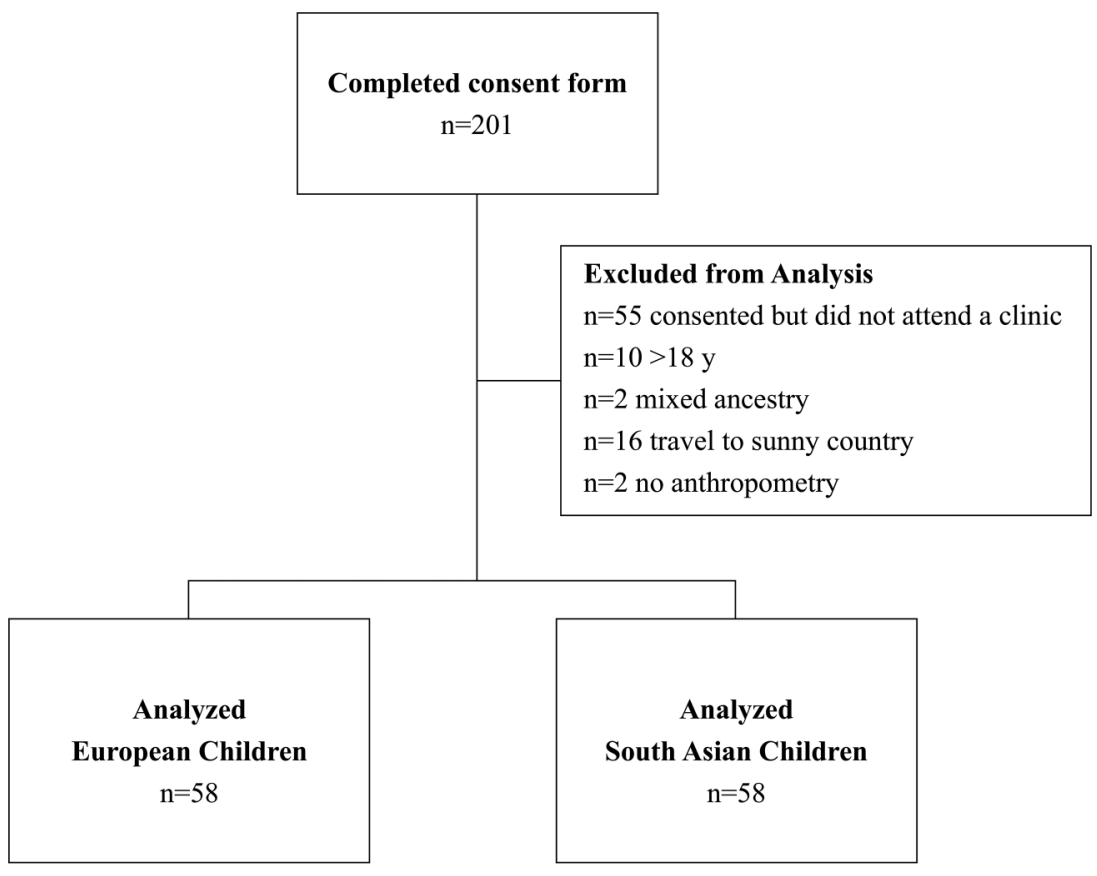

Commission on Illumination (CIE) $\mathrm{L}^{*} \mathrm{a}^{*} \mathrm{~b}^{*}$ colour scale (Chardon et al. 1991; Del Bino and Bernerd 2013). The $\mathrm{L}^{*}$ and $\mathrm{b}^{*}$ values were also transformed into individual typology angles $\left(\mathrm{ITA}^{\circ}\right)$ using the following equation: $\mathrm{ITA}^{\circ}=$ Arctangent $\left[\left(\mathrm{L}^{*}-50\right) / \mathrm{b}^{*}\right] \times 180 / \Pi($ Del Bino and Bernerd 2013).

\section{Serum 250HD analysis}

Serum total 25OHD was measured using liquid chromatography tandem mass spectrometry (MS). In brief, internal standards (25-hydroxyvitamin $\mathrm{D}_{3}-\left[23,24,25,26,27-{ }^{13} \mathrm{C}_{5}\right] ; 25$-hydroxyvitamin $\mathrm{D}_{2}$ $\left[25,26,27-{ }^{13} \mathrm{C}_{3}\right]$; 3-epi-25-hydroxyvitamin $\mathrm{D}_{3}-\left[23,24,25,26,27-{ }^{13} \mathrm{C}_{5}\right]$, CertiMass Reference Standards (IsoSciences, Ambler, PA, USA) were added to $150 \mu \mathrm{L}$ of serum. $\mathrm{ZnSO}_{4}(150 \mu \mathrm{L}$ of $0.2 \mathrm{M})$ and methanol $(600 \mu \mathrm{L})$ were added to denature and precipitate proteins followed by centrifugation. Extraction of vitamin D metabolites from the supernatant was performed using solid phase extraction (Waters Oasis HLB $\mu$ Elution 96-well plate). Supernatant $(600 \mu \mathrm{L})$ was added to the extraction plate, washed with $200 \mu \mathrm{L}$ of $5 \%$ and $60 \%$ methanol, then eluted and collected with $80 \mu \mathrm{L}$ of $95 / 5$ methanol/isopropanol $(v / v)$ followed by $50 \mu \mathrm{L}$ of water. Three analytes $\left(25 \mathrm{OHD}_{3}, 25 \mathrm{OHD}_{2}\right.$ and the C-3 epimer) were separated isocratically on a Waters Acquity HSS PFP UPLC column $(1.8 \mu \mathrm{m}, 2.1 \times 100 \mathrm{~mm})$ using 68/32 methanol/water $(v / v)$ with a limit of detection of $<3 \mathrm{nmol} / \mathrm{L}$. The MS/MS ion transitions were interpreted against a 5-point calibration curve and concentrations calculated based on the response of the internal standards. The laboratory is certified through the Vitamin D Standardization Certification Program as being traceable to the internationally recognized reference measurement procedure (https://www.cdc.gov/labstandards/vdscp.html) (Sempos et al. 2017; Wise et al. 2017) with an overall method bias (accuracy) of $0.2 \%$ and a precision of $7.1 \%$. The laboratory has maintained annual certification of proficiency in the Vitamin D External Quality Assessment Scheme since 2005 and through the College of American Pathologists since 2012.

\section{Statistical analyses}

The study was designed to determine serum 250HD levels in free-living children. The analysis was conducted using predetermined potential contributing factors: ethnicity, skin colour, age, sex, vitamin D intake (food + supplements), and BMI (all measures taken at clinic visit or through completion of an on-line questionnaire). No other factors were identified or included in the final analysis. This work was part of a larger study that included cardiovascular risk factors. As such, blood lipids were measured but are not reported here (data not published).

Based on our previous adult study (Nagasaka et al. 2018), a difference of $23 \mathrm{nmol} / \mathrm{L}$ was observed between ethnic groups in the spring. Assuming a SD of 25 to permit for the possibility of greater variation in children, a sample estimate of 19 per group would provide for $80 \%$ power with $\alpha$ set at 0.05 and double-sided testing. A larger sample was sought to support subgroup analyses (age, sex). For continuous variables, differences between ethnic groups were compared using a mixed model ANOVA (proc MIXED; SAS Enterprise Guide v7.15; SAS Institute, Cary, NC) with fixed effects of ethnic group and random effects of the individual in lieu of no information on socioeconomic status (family income, parental education level). For variables with more than 2 levels, post hoc Tukey's $t$ tests were used to identify differences among means or for interaction terms while adjusting for multiple comparisons. For proportions, $\chi^{2}$ analyses were used. Only 2 children in the European group vs. 10 in the South Asian group were in the obese category. Thus, the proportion of children in the overweight and obese categories were combined. Likewise, 2 European children were in the risk for underweight BMI category and included in an underweight/healthy BMI group.

Factor analysis was performed using a type 1 general linear model (SAS proc GLM). The order of factors for the GLM analysis was as follows: quartiles of total vitamin D intake; ethnicity (European or South Asian); the interaction: quartiles of total vitamin $D$ intake $\times$ ethnicity; BMI category (risk of underweight + healthy weight vs overweight + obese); the interaction: BMI category $\times$ ethnicity; and age category (6-13 y vs 14-18 y). Serum $250 H D$ concentrations were log transformed prior to analysis. Post hoc comparisons were performed using Tukey's tests adjusted for multiple comparisons $(P<0.05)$.

\section{Results}

Overall, 116 children from 6.3 to 18.9 years of age participated in this study. A greater proportion of children in the South Asian 
Table 1. Participant characteristics.

\begin{tabular}{|c|c|c|c|}
\hline Variable & European $(n=58)$ & South Asian $(n=58)$ & $P$-value \\
\hline Born in Canada, $n(\%)$ & $52(89.7)$ & $28(48.3)$ & $<0.0001$ \\
\hline Male sex, $n(\%)$ & $30(51.7)$ & $25(43.1)$ & 0.353 \\
\hline Age & $13.3 \pm 3.4$ & $13.7 \pm 3.2$ & 0.522 \\
\hline $6-13 \mathrm{y}, n(\%)$ & $30(51.7)$ & $27(46.6)$ & 0.578 \\
\hline $14-18.9 y, n(\%)$ & $28(48.3)$ & $31(53.4)$ & \\
\hline Height Z-score & $0.29 \pm 0.91$ & $-0.03 \pm 1.08$ & 0.116 \\
\hline BMI Z-score & $0.10 \pm 1.13$ & $0.56 \pm 1.24$ & 0.059 \\
\hline Underweight/healthy BMI, $n$ (\%) & 45 (77.6) & $35(60.3)$ & 0.047 \\
\hline Overweight/obese BMI, $n(\%)$ & $13(22.4)$ & $23(39.7)$ & \\
\hline \multicolumn{4}{|l|}{ Upper inner arm ITA $^{\circ}$} \\
\hline Median (IQR) & $62.9(47.6-58.7)$ & $15.9(1.6-31.0)$ & $<0.0001$ \\
\hline Mean \pm SD & $53.8 \pm 7.1$ & $16.4 \pm 17.4$ & \\
\hline \multicolumn{4}{|l|}{ Vitamin D intake from food, IU/d } \\
\hline Median (IQR) & $295(193-393)$ & $259(147-401)$ & 0.999 \\
\hline Mean \pm SD & $298 \pm 147$ & $286 \pm 172$ & \\
\hline \multicolumn{4}{|c|}{ Vitamin D intake from supplements, IU/d } \\
\hline Median (IQR) & $0(0-370)$ & $0(0-55)$ & 0.054 \\
\hline Mean \pm SD & $281 \pm 508$ & $136 \pm 274$ & \\
\hline \multicolumn{4}{|l|}{ Total vitamin D intake (IU/d) } \\
\hline Median (IQR) & $423(209-734)$ & $309(168-501)$ & 0.054 \\
\hline Mean \pm SD & $579 \pm 517$ & $423 \pm 328$ & \\
\hline \multicolumn{4}{|c|}{ Servings* fortified milk or plant beverages, $n$ (\%) } \\
\hline$<2 / \mathrm{d}$ & $30(51.7)$ & $38(65.5)$ & 0.133 \\
\hline$\geq 2 / \mathrm{d}$ & $28(48.3)$ & $20(34.5)$ & \\
\hline \multicolumn{4}{|l|}{ Serum total $25 \mathrm{OHD}$} \\
\hline$<40 \mathrm{nmol} / \mathrm{L}, n(\%)$ & $5(8.6)$ & $33(56.9)$ & $<0.0001$ \\
\hline$\geq 40 \mathrm{nmol} / \mathrm{L}, n(\%)$ & $53(91.4)$ & $25(43.1)$ & \\
\hline
\end{tabular}

Note: Data are mean \pm SD, median (IQR), or $n$ (\%). Differences among groups tested using mixed-model ANOVA or $\chi^{2}$ tests. 25OHD, 25-hydroxyvitamin D, BMI, body mass index; ITA ${ }^{\circ}$, individual topology angle.

${ }^{*} \mathrm{~A}$ serving is $250 \mathrm{~mL}$.

group were born outside of Canada with 12 of 28 immigrating $\leq 5 \mathrm{y}$ prior to the study (range 1.5 to $14 \mathrm{y}$ ). Within the European group, those that immigrated to Canada $(n=6)$ did so 8 to 14 y prior to the study (Table 1). The groups had similar proportions of males and females as well as similar proportions of children within each age category. Mean height and BMI Z-scores were within normal limits. The proportion of children in the overweight and obese categories (combined) was higher in the South Asian study group. Skin pigmentation based on $\mathrm{ITA}^{\circ}$ of the inner upper arm was within the range of very light for the European group and consistent with more melanin pigmentation in the South Asian group (Table 1). The ITA $^{\circ}$ values had a wider distribution in the South Asian group and a portion of both groups overlapped (Supplementary Fig. S1 ${ }^{1}$ ).

Intake of vitamin $\mathrm{D}$ from food over the $30 \mathrm{~d}$ prior to the study (Table 1) did not differ between ethnic groups. Supplements were used more frequently by the European group $(n=29,50 \%)$ compared with the South Asian group $(n=18,31 \%)$. Median intakes of supplemental vitamin $\mathrm{D}$, based on dose and frequency of use, were 400 (IQR 214.3-728.6) IU/d in European and 425 (IQR 142.9714.3) IU/d in South Asian children. Total vitamin D intake (reported food + supplement) was not significantly different between groups, although reported intakes were highly variable ranging from 63 to $3174 \mathrm{IU} / \mathrm{d}(n=116)$. In many of the files $(72 \%)$, parents helped with or filled out the FFQ but this did not affect the reported intake values $(P=0.44)$. Within the supplement users, median total vitamin $D$ intake was not different $(P=0.96)$ with European children consuming 758.2 (IQR 591.6-1005) and South Asian children consuming 865.3 (IQR 409.0-1003.0) IU/d. The main source of vitamin D from food was from vitamin D fortified milk or plant beverages, median intakes expressed as a percentage of total intake from food were 77.2\% (IQR 67.7-85.0) in the European and 72.9\% (IQR 60.7-83.5) in the South Asian groups. Smaller proportions of vitamin D from food were from fatty fish
(European 8.4\%, South Asian 14.4\%), meat (European 5.5\%, South Asian 4.1\%), eggs (European 3.1\%, South Asian 4.1\%) and margarine (European 3.7\%, South Asian 2.4\%). No differences in the number of children consuming $\geq 500 \mathrm{~mL} / \mathrm{d}$ of fortified milk or plant beverages were observed: overall median intakes were 1.5 (IQR: 1.0-2.9) servings $/ \mathrm{d}(1$ serving $=250 \mathrm{~mL})$.

Serum 25OHD distributions were skewed in both groups (Fig. 2). No children of European ethnicity had values below $30 \mathrm{nmol} / \mathrm{L}$ whereas 27.6\% of South Asian children fell below $30 \mathrm{nmol} / \mathrm{L} 25 \mathrm{OHD}$. The proportion of European children with serum $25 \mathrm{OHD} \geq 40 \mathrm{nmol} / \mathrm{L}$ was more than double $(91.4 \%$ vs. $43.1 \%, P<0.0001)$ that of the South Asian children (Table 1). Total vitamin D intake was lower in participants with $25 \mathrm{OHD}<40 \mathrm{nmol} / \mathrm{L}$ compared with those with $\geq 40 \mathrm{nmol} / \mathrm{L}$ (Fig. 3, top panel). BMI Z-score was highest in South Asian children with $25 \mathrm{OHD}<40 \mathrm{nmol} / \mathrm{L}$ compared with those $\geq 40 \mathrm{nmol} / \mathrm{L}$ as well as in European children regardless of vitamin D status (Fig. 3, bottom panel). Within supplement users, vitamin D status was not different among groups (European $61.9 \pm 17.4 \mathrm{nmol} / \mathrm{L}$ vs. South Asian $53.2 \pm 17.0 \mathrm{nmol} / \mathrm{L}, P=0.10$ ) and none had serum $25 \mathrm{OHD}$ values $<30 \mathrm{nmol} / \mathrm{L}$. Supplement use was associated with an increased frequency of South Asians having serum 25OHD above $40 \mathrm{nmol} / \mathrm{L}$ (78\% vs. 28.8\%; Supplementary Fig. S2 ${ }^{1}$ ) and a higher average serum $25 \mathrm{OHD}$ concentration (Supplementary Fig. S3 ${ }^{1}$ ).

In a multi-factorial Type 1 linear model (Table 2), 54\% of the variation in log-transformed serum 25OHD was accounted for; serum 25OHD was lower in South Asian children and older children. A type 1 model was used in an attempt to separate the highly correlated upper inner arm skin colour ITA $^{\circ}$ values from ethnicity. No effect of skin colour was anticipated since serum 25OHD was measured in the spring to negate the effect of sun exposure. However, an effect was possible since a study with South Asian adults showed that summer and winter serum $250 \mathrm{HD}$ values are highly correlated (Nagasaka et al. 2018). When ITA ${ }^{\circ}$ was included 
Fig. 2. Distribution of serum 25OHD in European and South Asian children. Bars represent the percentage of each ethnic group falling within indicated intervals (top left panel: South Asians; top right panel: Europeans). The frequency values were also plotted as midpoints of the intervals (bottom panel). Darker circles represent values for South Asians while lighter triangles represent values for Europeans ( $n=58$ per ethnic group).



in the model, it was not significant $(P=0.29)$ showing that ethnicity adequately accounted for its effect. Separate analysis of the 2 ethnic groups showed that, despite the wide range of ITA $^{\circ}$ values in children of South Asian descent, including some overlap with the European ITA ${ }^{\circ}$ values (Supplementary Fig. $\mathrm{S1}^{1}$ ), $\mathrm{ITA}^{\circ}$ was not a significant correlate of 25OHD concentrations in South Asian children $(P=0.57)$. A similar analysis restricted to European children gave the same result $(P=0.81)$. Country of birth $(P=0.39)$, and sex $(P=0.51)$ were also non-significant and were thus excluded from the final model. Ethnicity and age groups showed no significant 3-way interactions with either BMI category, dietary vitamin D intakes (quartiles), or supplement use (Yes vs. No). These 3-way interactions were also excluded from the model. In the final model, total vitamin D intake and ethnicity accounted for $42 \%$ of the total variance, with the other factors accounting for about $12 \%$ (see semi-partial $\eta^{2}$; Table 2). Serum 25OHD values were lower in South Asian children compared with European children in the first 3 quartiles of intake but similar at the highest quartile of vitamin D intakes (Fig. 4). Interactions between ethnic group and BMI category suggested that, in the underweight/healthy category, South Asian children had lower serum 25OHD than did European children. Having an overweight/obese BMI was associated with lower 25OHD only in South Asian children. The absence of lower serum 25OHD in overweight/obese Europeans may be more reflective of the small sample size in the present study since only $22 \%$ of Europeans fell in this category.

\section{Discussion}

This study was primarily designed to explore vitamin D status in South Asian children in relation to dietary and supplemental vitamin D intake in the absence of solar ultraviolet B (UVB)
Fig. 3. Median (IQR) total vitamin D intake over $30 \mathrm{~d}$ estimated using food frequency questionnaire (top panel) and body mass index Z-score (bottom panel) according to ethnicity and the population vitamin D status cut-point of $40 \mathrm{nmol} / \mathrm{L}$ of 25OHD. Data ( $n=58$ per ethnic group) were tested using mixed-model ANOVA, top panel: ethnicity $P=0.8011$, status category $P=0.0062$, interaction $P=0.5798$; bottom panel: ethnicity $P=0.0590$, status category $P=0.5789$, interaction $P=0.0225$; ${ }^{*} P<0.01,{ }^{* *} P<0.02$.
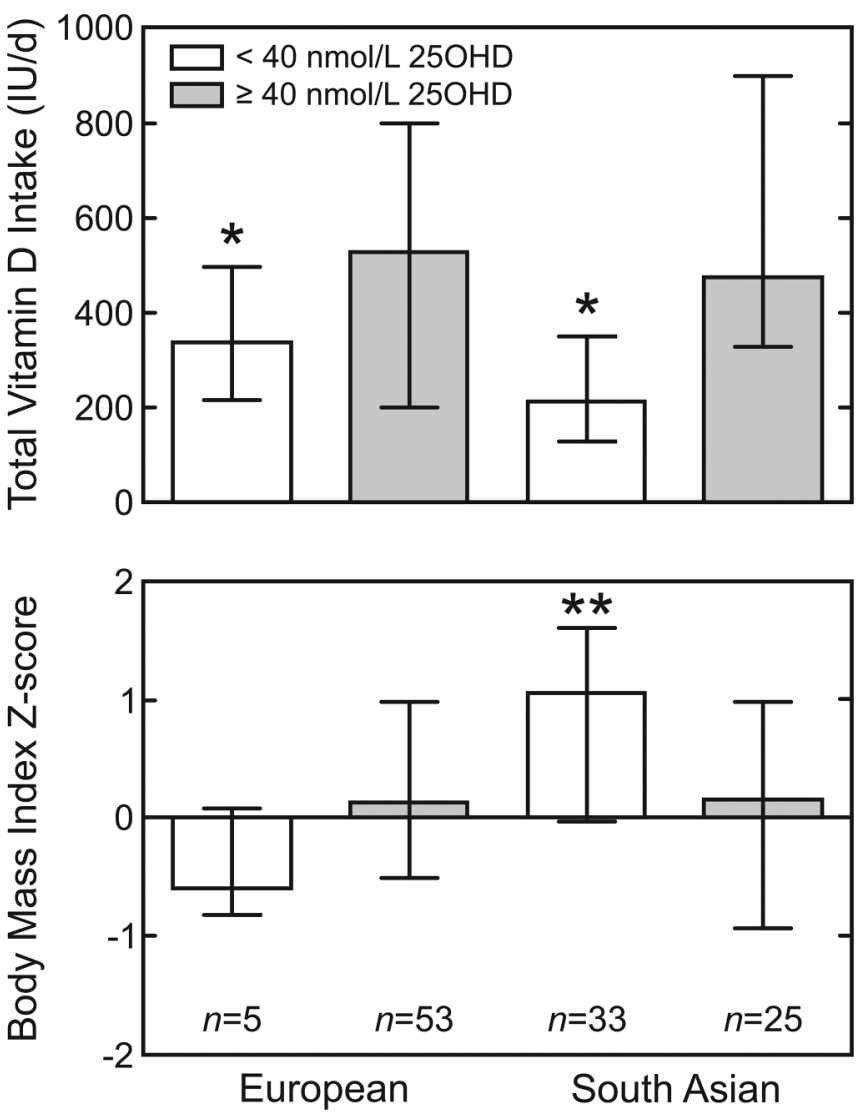

radiation exposure. The proportion of South Asian children with serum 25OHD concentrations below the $40 \mathrm{nmol} / \mathrm{L}$ population status cut-point for inadequate vitamin D status was $56.9 \%$ compared with $8.6 \%$ in the European group. These results are similar to a previous survey in adults where $29.1 \%$ of women and $44.2 \%$ of men of South Asian ethnicity were below this cut-point in the spring (Nagasaka et al. 2018). These values also compare well to those from children ( 6 to 17 y) in the Canadian Health Measures Survey from 2007-2011. In that survey, 8.6\% (6.4, 11.4\%) of white children had serum 25OHD below $40 \mathrm{nmol} / \mathrm{L}$ (Greene-Finestone et al. 2017) vs. $29.8 \%(20.1,41.8 \%)$ for non-white children (crosssectional design over the year). The higher proportion of South Asian children $<40 \mathrm{nmol} / \mathrm{L}$ in the present study may be due to lower 25OHD status at the end of the summer as has been observed for South Asian adults when compared with European adults (Nagasaka et al. 2018). Lower vitamin D status at the start of winter was highly correlated with $25 \mathrm{OHD}$ values at the end of winter (Brooks et al. 2017). In a similar analysis of Canadian Health Measures Survey data (Whiting et al. 2011), the proportion of non-white children 12-19 years of age with $25 \mathrm{OHD}<40 \mathrm{nmol} / \mathrm{L}$ in the winter was $48.2 \%(24.9,72.2 \%)$. Thus, the present crosssectional analysis, while not representative of all Canadian children, enabled us to gain insight regarding the divergent vitamin D status within the South Asian population. In addition, it provides 
Table 2. Serum 25OHD concentration according to vitamin D intake, ethnicity, body mass index, and age.

\begin{tabular}{|c|c|c|c|c|c|}
\hline Variable & $\begin{array}{l}\text { European } \\
(n=58)\end{array}$ & $\begin{array}{l}\text { South Asian } \\
(n=58)\end{array}$ & Variables in model & $P$-value & $\begin{array}{l}\text { Semi- } \\
\text { partial } \eta^{2}\end{array}$ \\
\hline \multicolumn{6}{|l|}{ Total vitamin D intake (IU/d)* } \\
\hline Quartile 1: 62.4 to $<201.6$ & $52.3 \pm 4.2 \mathrm{~cd}$ & $30.0 \pm 3.1 \mathrm{a}$ & Total intake & $<0.0001$ & 0.197 \\
\hline Quartile 2: 201.6 to $<377.0$ & $57.1 \pm 4.1 \mathrm{~cd}$ & $33.3 \pm 3.3 \mathrm{ab}$ & Intake $\times$ ethnicity & 0.012 & 0.050 \\
\hline Quartile 3: 377.0 to $<649.8$ & $58.3 \pm 2.9 \mathrm{~d}$ & $42.1 \pm 4.1 \mathrm{bc}$ & & & \\
\hline Quartile 4: 649.8 to 3174.1 & $63.5 \pm 5.1 d$ & $55.3 \pm 4.5 \mathrm{~cd}$ & & & \\
\hline Ethnicity & $58.4 \pm 15.8 \mathrm{~A}$ & $39.0 \pm 16.8 \mathrm{~B}$ & Ethnicity & $<0.0001$ & 0.222 \\
\hline \multicolumn{6}{|l|}{ Body mass index } \\
\hline Underweight/healthy & $59.1 \pm 17.2 \mathrm{~A}$ & $42.3 \pm 17.1 \mathrm{~A}$ & BMI category & 0.028 & 0.021 \\
\hline Overweight/obese & $56.1 \pm 9.7 \mathrm{~B}$ & $34.1 \pm 15.4 \mathrm{~B}$ & BMI $\times$ ethnicity & 0.193 & 0.007 \\
\hline \multicolumn{6}{|l|}{ Age category } \\
\hline $6-13 y$ & $61.6 \pm 15.8 \mathrm{~A}$ & $44.7 \pm 18.5 \mathrm{~A}$ & Age & 0.001 & 0.047 \\
\hline $14-18.9 y$ & $55.0 \pm 15.3 \mathrm{~B}$ & $34.1 \pm 13.7 \mathrm{~B}$ & & & \\
\hline
\end{tabular}

Fig. 4. Ethnicity and vitamin D intake in relation to serum 25OHD concentration. Points represent means \pm SEM for quartiles of vitamin D intake (black filled circles for South Asians; white filled triangles for Europeans). Within each ethnicity, points with different letters differ significantly at the $P<0.05$ level as determined from the type 1 general linear model regression with post hoc comparisons. See Table 2 for quartile intake ranges.

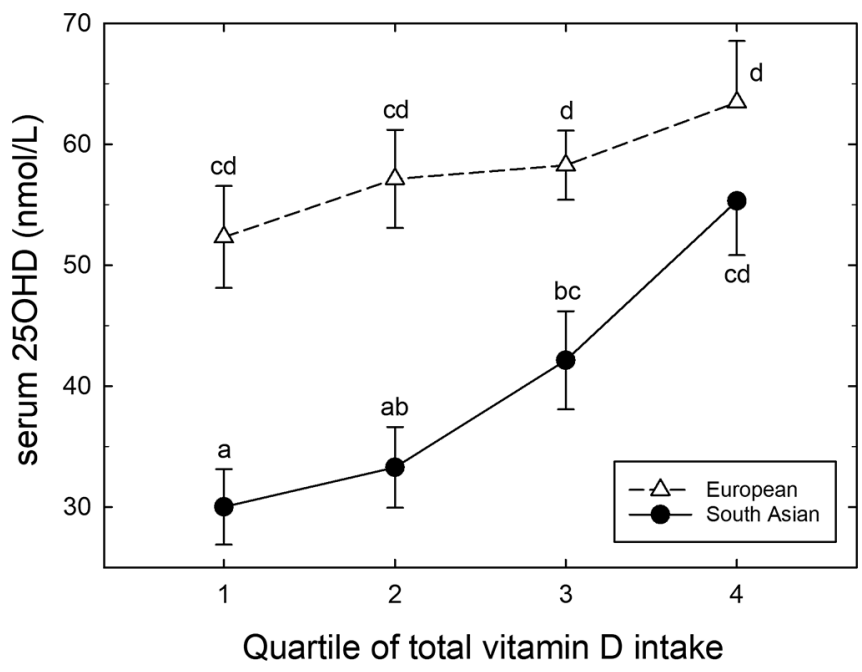

information on sample sizes required to target other lower-prevalence groups for future Canadian national-level surveys.

Dietary vitamin D intakes, estimated using our 30-d FFQ, suggested no differences existed between the South Asian and European children with median intakes similar to national statistics (Health Canada and Minister of Health 2009). On the other hand, total vitamin D intakes (including supplement use) tended to be higher in European children $(P=0.054)$ - an effect due largely to the contribution of supplements (Table 1). The difference in total intake between the ethnic groups is due to a higher proportion of supplement users among European children (50 vs. 31\%, $P=$ 0.0389). Supplement use was related to serum 25OHD: total vitamin D intake was lower in participants with $25 \mathrm{OHD}<40 \mathrm{nmol} / \mathrm{L}$.

Among supplement users, total vitamin D intake and vitamin D status were not different between our ethnic groups, and serum $25 \mathrm{OHD}$ was on average above $50 \mathrm{nmol} / \mathrm{L}$. Recent trials in South Asian children suggest that long-term intakes that meet the EAR of $400 \mathrm{IU} / \mathrm{d}$ of vitamin from food and supplemental intakes will support vitamin D status targets of $40 \mathrm{nmol} / \mathrm{L}$ or more even if vitamin D intake and status are low at baseline. For example, in young female Pakistani immigrants (12 y) in Denmark with median vitamin D intakes of $80 \mathrm{IU} / \mathrm{d}$ and $\sim 25 \%$ overweight/obese, an additional vitamin D supplement of $400 \mathrm{IU} / \mathrm{d}$ elevated serum 25OHD from below $20 \mathrm{nmol} / \mathrm{L}$ to $46 \mathrm{nmol} / \mathrm{L}$ over 1 year (Andersen et al. 2008). Similarly, in East Indian children 6-16 years of age, with $27 \%$ in the overweight/obese category, supplemental intakes of $600 \mathrm{IU} / \mathrm{d}$ for 6 months elevated serum 250HD from a baseline of $24 \mathrm{nmol} / \mathrm{L}$ to $61 \mathrm{nmol} / \mathrm{L}$ (Marwaha et al. 2019). Thus, usual vitamin D intakes that approximate the EAR of $400 \mathrm{IU} / \mathrm{d}$ appear to be sufficient to support population targets for vitamin D status in children regardless of ethnicity.

In the present study, the main source of dietary vitamin D was from vitamin $\mathrm{D}$ fortified milk with dietary vitamin $\mathrm{D}$ intakes consistent with national surveillance datasets (Hosseini et al. 2019). Even though the 30-d FFQ used in our study prevents direct comparison to the EAR, it is notable that the $75^{\text {th }}$ percentile of dietary intakes in South Asian group was below the EAR. Whether meeting the EAR from food would improve vitamin D status to population targets has not been tested in South Asian children in Canada. However, in young children (2-8 y) in Montreal, meeting the EAR of $400 \mathrm{IU} / \mathrm{d}$ in the winter through vitamin $\mathrm{D}$ fortified foods supported maintenance of vitamin D status above $40 \mathrm{nmol} / \mathrm{L}$ and the response did not vary according to ethnicity (Brett et al. 2016). Another trial in 12-year-old East Indian children living in New Delhi (Khadgawat et al. 2013) showed that consumption of vitamin D fortified milk (600 IU/d) increased serum 250HD from 29 to $57 \mathrm{nmol} / \mathrm{L}$ after 12 weeks. Canada has proposed new fortification regulations that would increase the amount of vitamin D added to milk and margarine (Government of Canada 2018, 2021). Greater amounts of vitamin D in the food supply may thus help to improve vitamin D status of South Asian children.

As previously summarized, BMI is often elevated in children of South Asian ethnicity and at a given BMI, the proportion of adipose tissue mass is increased (Hudda et al. 2017). In addition, visceral adiposity was the strongest predictor of divergent vitamin D status in South Asian adults (Sulistyoningrum et al. 2012). In the present analysis, the proportion of children in the combined overweight and obese category was greater in the South Asian children, with an overall BMI Z-score of 0.56 . This is very similar to a study conducted in 2 Canadian provinces (British Columbia and Ontario) reporting an average BMI Z-score of 0.48 among 762 elementary and high school students (Fowokan et al. 2019). While vitamin D status was lower in our South Asian children, it was even lower in South Asian children 
with a BMI in the overweight and obese categories (Table 2). In the children with $25 \mathrm{OHD}<40 \mathrm{nmol} / \mathrm{L}, \mathrm{BMI}$ Z-score was significantly higher in the South Asian children. In our study, the percentage of children that fell into the overweight/obese category was higher for those of South Asian ethnicity (40\%) compared with those of European ethnicity (22\%). This is in line with other Canadian data where children of European descent had lower odds for falling in the overweight/obese category (Rodd and Sharma 2016). Note that the BMI Z-score is not an ideal measure of adiposity for individuals since it was developed to assess populations rather than individuals. In addition, the relationship between the BMI and the prevalence of overweight/obese is ethnicity-dependent and underestimated the prevalence in South Asian children (Hudda et al. 2018). The question of whether visceral adiposity better explains the lower vitamin D status will require further investigation. Future cycles of the Canadian Health Measures Survey will help to clarify these data, as body composition will be measured using dual-energy X-ray absorptiometry that include estimates of visceral fat.

The findings of this study support previous studies of the Canadian population where increasing levels of adiposity associated with higher proportions of Canadian children with 25OHD $<40 \mathrm{nmol} / \mathrm{L}$ (Greene-Finestone et al. 2017), potentially due to sequestration of vitamin D in adipose tissue (Blum et al. 2008). This situation is not unique to Canada. Relatively higher BMI values and lower 25OHD levels have recently been reported in a New Zealand study (Delshad et al. 2019) and the issue of lower vitamin D status of South Asian people in northern countries is well established (Darling 2020). The issue is important because a relationship between lower status and disease markers has been demonstrated even in children (Delshad et al. 2020; Julies et al. 2020; Tahmasebi et al. 2020; Tang et al. 2020). Combined, these studies strengthen the importance of public health programs designed to reduce childhood obesity.

An advantage of this study is the reliance on Vitamin D Standardization Program certified measures in assessing vitamin D status. Standardizing vitamin D measures is important for comparison with other standardized measures, such as the Canadian Health Measures Survey and the National Health and Nutrition Examination Survey, since there can be considerable variability among platforms and even temporally within the same survey (Sempos and Binkley 2020). In addition, standardization allows the pooling of research data without measurement bias (Sempos et al. 2018).

This study has important limitations to consider. The sample size was relatively small, and spanned a wide age range from as young as 6.3 to $18.9 \mathrm{y}$. To help mitigate this, we limited the number of covariates tested within a model. In addition, important sociodemographic factors (parent education, family income, etc.) were unavailable and should be included in future studies. Furthermore, only 2 children in the comparison group had a BMI in the obese range preventing analysis according to healthy, overweight or obese weight status. While vitamin D status of the children was similar to national surveillance studies, comparison with other studies is difficult, since values standardized against the Vitamin D Standardization Certification Program (as used in the present analysis) have not been universally reported. Even though the dietary questionnaire used in this study was targeted to vitamin D containing foods likely to be consumed by the participants, the FFQ method is only semi-quantitative given multiple sources of error in children (recall bias, incorrect portion size estimation, boredom with long surveys, etc.; Perez-Rodrigo et al. 2015). Lastly, while the intent was to explore correlates of vitamin D status in the absence of solar UVB radiation exposure, lack of a summer or early fall time-point precluded assessment of potential declines in vitamin $\mathrm{D}$ stores to help explain the $\sim 20 \mathrm{nmol} / \mathrm{L}$ difference between the groups. Nonetheless, the magnitude of difference is in line with National statistics for white and non-white children that span multiple seasons (Greene-Finestone et al. 2017; Whiting et al. 2011).
In summary, a greater proportion of children of South Asian descent had inadequate vitamin $\mathrm{D}$ status. Inadequate vitamin $\mathrm{D}$ status in South Asian children associated with lower total exogenous intakes of vitamin D and higher BMI Z-scores. By conducting the study in the winter, we were able to examine exogenous intakes without the impact of recent solar UVB radiation exposure and associated endogenous source of vitamin D. Based on trials of increasing vitamin D intakes through supplements or fortified foods (Andersen et al. 2008; Brett et al. 2016; Khadgawat et al. 2013; Marwaha et al. 2019), and the supplement users subgroup analysis of our study, South Asian children who meet the EAR of $400 \mathrm{IU} / \mathrm{d}$ of vitamin D also achieved the population target of $40 \mathrm{nmol} / \mathrm{L}$ of $25 \mathrm{OHD}$. This study reinforces the importance of public health actions towards meeting vitamin $\mathrm{D}$ intake recommendations.

\section{Conflict of interest statement}

The authors report no conflicts of interest.

\section{Acknowledgements}

The authors wish to thank all those who participated in the study. The authors also acknowledge the following individuals who helped at the clinics and/or with design elements of the study: Lois Fernandez, Judy Green, Penny Jee, Nadine Kebbe, Cindy Levert, Isabelle Massarelli, Paula Roach, Sarah Rostami, Keith Snider, and Carla Wood. This study was funded by Health Canada. Author contributions: W.M.N.R., I.R., E.S., and K.S. designed the study; W.M.N.R. and E.S. recruited participants; S.P. J.B., W.M.N.R., I.R., E.S., and K.S. participated at the clinics; I.R., E.S., and K.S. analyzed the samples/survey information; H.A.W. and S.P.J.B. created the database, performed the statistical analyses, and drafted the manuscript; W.M.N.R., I.R., E.S., and K.S. provided critical input into the manuscript.

\section{References}

Andersen, R., Molgaard, C., Skovgaard, L.T., Brot, C., Cashman, K.D., Jakobsen, J., et al. 2008. Effect of vitamin D supplementation on bone and vitamin D status among Pakistani immigrants in Denmark: a randomised double-blinded placebo-controlled intervention study. Br. J. Nutr. 100(1): 197-207. doi:10.1017| S000711450789430X. PMID:18208636.

Blum, M., Dolnikowski, G., Seyoum, E., Harris, S.S., Booth, S.L., Peterson, J., et al. 2008. Vitamin D(3) in fat tissue. Endocrine, 33(1): 90-94. doi:10.1007| s12020-008-9051-4. PMID:18338271.

Brett, N.R., Lavery, P., Agellon, S., Vanstone, C.A., Maguire, J.L., Rauch, F., et al. 2016. Dietary vitamin D dose-response in healthy children 2 to $8 \mathrm{y}$ of age: a 12-wk randomized controlled trial using fortified foods. Am. J. Clin. Nutr. 103(1): 144-152. doi:10.3945/ajcn.115.115956. PMID:26675772.

Brooks, S.P.J., Greene-Finestone, L., Whiting, S., Fioletov, V.E., Laffey, P., and Petronella, N. 2017. An analysis of factors associated with 25-hydroxyvitamin D levels in White and non-White Canadians. J. AOAC Int. 100(5): 1345-1354. doi:10.5740/jaoacint.17-0250. PMID:28776491.

Canadian Institutes of Health Research Natural Sciences and Engineering Research Council of Canada and Social Sciences and Humanities Research Council. 2018. Tri-Council Policy Statement: Ethical Conduct for Research Involving Humans. Secretariat on Responsible Conduct of Research, Ottawa, Ont, Canada. Available from https://ethics.gc.ca/eng/documents/tcps2-2018-eninteractive-final.pdf.

Chardon, A., Cretois, I., and Hourseau, C. 1991. Skin colour typology and suntanning pathways. Int. J. Cosmet. Sci. 13(4): 191-208. doi:10.1111/j.14672494.1991.tb00561.x. PMID:19291061.

Darling, A.L. 2020. Vitamin D deficiency in western dwelling South Asian populations: an unrecognised epidemic. Proc. Nutr. Soc. 79(3): 259-271. doi:10.1017/S0029665120000063. PMID:32046797.

Del Bino, S., and Bernerd, F. 2013. Variations in skin colour and the biological consequences of ultraviolet radiation exposure. Br. J. Dermatol. 169(Suppl. 3): 33-40. doi:10.1111/bjd.12529. PMID:24098899.

Delshad, M., Beck, K.L., Conlon, C.A., Mugridge, O., Kruger, M.C., Jensen, B.P., et al. 2019. Wintertime Vitamin D status and its related risk factors among children living in Auckland, New Zealand. N. Z. Med. J. 132: 67-76. PMID:31647796.

Delshad, M., Beck, K.L., Conlon, C.A., Mugridge, O., Kruger, M.C., and von Hurst, P.R. 2020. Fracture risk factors among children living in New Zealand. J. Steroid Biochem. Mol. Biol. 200: 105655. doi:10.1016/j.jsbmb. 2020.105655. PMID:32171787. 
Eyre, E.L., Duncan, M.J., and Nevill, A. 2017. South Asian children have increased body fat in comparison to white children at the same body mass index. Children, 4(11): 102. doi:10.3390/children4110102. PMID:29165375.

Fowokan, A.O., Punthakee, Z., Waddell, C., Rosin, M., Morrison, K.M., Gupta, M., et al. 2019. Adiposity measures and their validity in estimating risk of hypertension in South Asian children: a cross-sectional study. BMJ Open, 9(2): e024087. doi:10.1136/bmjopen-2018-024087. PMID:30787084.

Government of Canada. 2015. Canadian Nutrient File. Health Canada, Ottawa, Ont. Available from https://www.canada.ca/en/health-canada/services food-nutrition/healthy-eating/nutrient-data/canadian-nutrient-file-about-us.html.

Government of Canada. 2018. Canada Gazette, Part I, Volume 152, Number 6: Regulations amending certain regulations made under the Food and Drugs Act (nutrition symbols other labelling provisions, partially hydrogenated oils and vitamin D).

Government of Canada. 2021. Forward Regulatory Plan 2021-2023: Regulations amending certain regulations under the Food and Drugs Act healthy eating provisions including nutrition symbols, other labelling provisions, partially hydrogenated oils and vitamin D. Health Canada, Ottawa, Ont. Available from https://www.canada.ca/en/health-canada/corporate/ about-health-canada/legislation-guidelines/acts-regulations/forward-regulatoryplan/plan/healthy-eating-provisions-front-pack-labelling-other-labelling-provisionsindustrially-produced-trans-fats-vitamin-d.html. [Accessed 19 July 2021.]

Greene-Finestone, L.S., Garriguet, D., Brooks, S.P.J., Langlois, K., and Whiting, S.J. 2017. Overweight and obesity are associated with lower vitamin D status in Canadian children and adolescents. Paediatr Child Health, 22(8): 438-444. doi:10.1093/pch/pxx116. PMID:29479261.

Health Canada and Minister of Health. 2009. Canadian Community Health Survey, Cycle 2.2, Nutrition (2004) - Nutrient Intakes from Food, Provincial, Regional and National Summary Data Tables. Available from https://www. canada.ca/en/health-canada/services/food-nutrition/food-nutrition-surveillance/ health-nutrition-surveys/canadian-community-health-survey-cchs/canadiancommunity-health-survey-cycle-2-2-nutrition-focus-food-nutrition-surveillancehealth-canada.html.

Hosseini, Z., Whiting, S.J., and Vatanparast, H. 2019. Canadians' dietary intake from 2007 to 2011 and across different sociodemographic/lifestyle factors using the Canadian Health Measures Survey Cycles 1 and 2. J. Nutr. Metab. 2019: 2831969. doi:10.1155/2019/2831969. PMID:30867963.

Hudda, M.T., Nightingale, C.M., Donin, A.S., Fewtrell, M.S., Haroun, D., Lum, S., et al. 2017. Body mass index adjustments to increase the validity of body fatness assessment in UK Black African and South Asian children. Int. J. Obes. 41(7): 1048-1055. doi:10.1038/ijo.2017.75. PMID:28325931.

Hudda, M.T., Nightingale, C.M., Donin, A.S., Owen, C.G., Rudnicka, A.R., Wells, J.C.K., et al. 2018. Patterns of childhood body mass index (BMI), overweight and obesity in South Asian and black participants in the English National child measurement programme: effect of applying BMI adjustments standardising for ethnic differences in BMI-body fatness associations. Int. J. Obes. 42(4): 662-670. doi:10.1038/ijo.2017.272. PMID:29093538.

Julies, P., Lynn, R.M., Pall, K., Leoni, M., Calder, A., Mughal, Z., et al. 2020. Nutritional rickets under 16 years: UK surveillance results. Arch. Dis. Child. 105(6): 587-592. doi:10.1136/archdischild-2019-317934. PMID:31949032.

Khadgawat, R., Marwaha, R.K., Garg, M.K., Ramot, R., Oberoi, A.K., Sreenivas, V., et al. 2013. Impact of vitamin D fortified milk supplementation on vitamin D status of healthy school children aged 10-14 years. Osteoporos. Int. 24(8): 2335-2343. doi:10.1007/s00198-013-2306-9. PMID:23460234.

Langlois, K., Greene-Finestone, L., Little, J., Hidiroglou, N., and Whiting, S. 2010. Vitamin D status of Canadians as measured in the 2007 to $2009 \mathrm{Ca}$ nadian Health Measures Survey. Health Rep. 21(1): 47-55. PMID:20426226.

Lee, S., Bountziouka, V., Lum, S., Stocks, J., Bonner, R., Naik, M., et al. 2014. Ethnic variability in body size, proportions and composition in children aged 5 to 11 years: Is ethnic-specific calibration of bioelectrical impedance required? PLoS One, 9(12): e113883. doi:10.1371/journal.pone.0113883. PMID:25478928.

Marwaha, R.K., Garg, M.K., Sethuraman, G., Gupta, N., Mithal, A., Dang, N., et al. 2019. Impact of three different daily doses of vitamin D3 supplementation in healthy schoolchildren and adolescents from North India: a single-blind prospective randomised clinical trial. Br. J. Nutr. 121(5): 538548. doi:10.1017/S0007114518003690. PMID:30843501.

Nagasaka, R., Swist, E., Sarafin, K., Gagnon, C., Rondeau, I., Massarelli, I., et al. 2018. Low 25-hydroxyvitamin D levels are more prevalent in
Canadians of South Asian than European ancestry inhabiting the National Capital Region of Canada. PLoS One, 13(12): e0207429. doi:10.1371/journal.pone.0207429. PMID:30540776.

Nightingale, C.M., Rudnicka, A.R., Owen, C.G., Donin, A.S., Newton, S.L., Furness, C.A., et al. 2013. Are ethnic and gender specific equations needed to derive fat free mass from bioelectrical impedance in children of South asian, black african-Caribbean and white European origin? Results of the assessment of body composition in children study. PLoS One, 8(10): e76426. doi:10.1371/journal.pone.0076426. PMID:24204625.

Perez-Rodrigo, C., Artiach Escauriaza, B., Artiach Escauriaza, J., and Polanco Allue, I. 2015. Dietary assessment in children and adolescents: issues and recommendations. Nutr. Hosp. 31(Suppl. 3): 76-83. doi:10.3305/nh.2015.31.sup3.8755. PMID: 25719775.

Rodd, C., and Sharma, A.K. 2016. Recent trends in the prevalence of overweight and obesity among Canadian children. CMAJ, 188(13): E313-E320. doi:10.1503/cmaj.150854. PMID:27160875.

Rosenbaum, M., Fennoy, I., Accacha, S., Altshuler, L., Carey, D.E., Holleran, S., et al. 2013. Racial/ethnic differences in clinical and biochemical type 2 diabetes mellitus risk factors in children. Obesity, 21(10): 2081-2090. doi:10.1002/ oby.20483. PMID:23596082.

Ross, A.C., Manson, J.E., Abrams, S.A., Aloia, J.F., Brannon, P.M., Clinton, S.K., et al. 2011. The 2011 report on dietary reference intakes for calcium and vitamin D from the Institute of Medicine: what clinicians need to know. J. Clin. Endocrinol. Metab. 96(1): 53-58. doi:10.1210/jc.2010-2704. PMID:21118827.

Sempos, C.T., and Binkley, N. 2020. 25-hydroxyvitamin D assay standardisation and vitamin D guidelines paralysis. Public Health Nutr. 23(7): 11531164. doi:10.1017/S1368980019005251. PMID:32301688.

Sempos, C.T., Betz, J.M., Camara, J.E., Carter, G.D., Cavalier, E., Clarke, M.W., et al. 2017. General steps to standardize the laboratory measurement of serum total 25-hydroxyvitamin D. J. AOAC Int. 100(5): 1230-1233. doi:10.5740/ jaoacint.17-0259. PMID:28766476.

Sempos, C.T., Heijboer, A.C., Bikle, D.D., Bollerslev, J., Bouillon, R., Brannon, P.M., et al. 2018. Vitamin D assays and the definition of hypovitaminosis D: results from the First International Conference on Controversies in Vitamin D. Br. J. Clin. Pharmacol. 84(10): 2194-2207. doi:10.1111/bcp.13652. PMID:29851137.

Sham, L., Yeh, E.A., Magalhaes, S., Parra, E.J., Gozdzik, A., Banwell, B., et al. 2015. Evaluation of fall Sun Exposure Score in predicting vitamin D status in young Canadian adults, and the influence of ancestry. J. Photochem. Photobiol. B, 145: 25-29. doi:10.1016/j.jphotobiol.2015.02.007. PMID:25752862.

Shaw, N.J., Crabtree, N.J., Kibirige, M.S., and Fordham, J.N. 2007. Ethnic and gender differences in body fat in British schoolchildren as measured by DXA. Arch. Dis. Child. 92(10): 872-875. doi:10.1136/adc.2007.117911. PMID:17522163.

Statistics Canada. 2017. Census Profile. 2016 Census. Statistics Canada, Ottawa, Ont.

Sulistyoningrum, D.C., Green, T.J., Lear, S.A., and Devlin, A.M. 2012. Ethnicspecific differences in vitamin D status is associated with adiposity. PLoS One, 7(8): e43159. doi:10.1371/journal.pone.0043159. PMID:22952641.

Tahmasebi, H., Asgari, S., Hall, A., Higgins, V., Chowdhury, A., Thompson, R., et al. 2020. Influence of ethnicity on biochemical markers of health and disease in the CALIPER cohort of healthy children and adolescents. Clin. Chem. Lab. Med. 58(4): 605-617. doi:10.1515/cclm-2019-0876. PMID:31874092.

Tang, Z., Huang, S., Ma, R., Zheng, H., and Zhu, Y. 2020. Low vitamin D status is associated with obesity but no other cardiovascular risk factors in Chinese children and adolescents. Nutr. Metab. Cardiovasc. Dis. 30(9): 1573-1581. doi:10.1016/j.numecd.2020.05.019. PMID:32605882.

Tugault-Lafleur, C.N., and Black, J.L. 2019. Differences in the quantity and types of foods and beverages consumed by Canadians between 2004 and 2015. Nutrients, 11(3): 526. doi:10.3390/nu11030526. PMID:30823448.

Whiting, S.J., Langlois, K.A., Vatanparast, H., and Greene-Finestone, L.S. 2011. The vitamin D status of Canadians relative to the 2011 Dietary Reference Intakes: an examination in children and adults with and without supplement use. Am. J. Clin. Nutr. 94(1): 128-135. doi:10.3945/ajcn.111.013268. PMID:21593503.

Wise, S.A., Phinney, K.W., Tai, S.S., Camara, J.E., Myers, G.L., Durazo-Arvizu, R., et al. 2017. Baseline assessment of 25-hydroxyvitamin D assay performance: a Vitamin D Standardization Program (VDSP) interlaboratory comparison study. J. AOAC Int. 100(5): 1244-1252. doi:10.5740/jaoacint.17-0258. PMID:28822355.

WHO. 2013. Child growth standards. World Health Organization (WHO), Geneva, Switzerland. 